\title{
Digital Mapping Techniques: A Vital Tool for Updating Topographic Maps in Nigeria (A Case Study of Okigwe Local Government Area in Imo State)
}

\author{
Augustine C. Emeribeole ${ }^{1}$, Chima J. Iheaturu ${ }^{2}$ \\ Department of Surveying and Geoinformatics, Imo State University, Owerri, Nigeria
}

\begin{abstract}
Most topographic maps in Nigeria were produced over forty years ago and are now obsolete. The rate of development that has taken place since then is enormous and cannot be ignored. Lack of updated topographic maps in Nigeria as a whole and Okigwe L.G.A in particular has affected many good intended government developmental projects, thereby affecting the decision making processes and planning.The traditional method of data collection for map making is laborious and it takes a longer time to produce which renders the map obsolete in real sense by the time the map is published.There is need therefore to produce maps from data that can portray reality as faithfully as possible, so that the rapid changes such as infrastructural development are accommodated in the maps. Digital mapping techniques offer such useful data gathering tool. When remotely sensed data are used to produce a map, it takes a new form, encourage new uses, new users, and cartographic visualization can be possible. Additionally, adequate software image manipulation and analysis can also be achieved.This paper brings to the fore the effectiveness of digital mapping techniques in updating the topographic map of Okigwe L.G.A at 1:50,000 scaleusing orthorectified SPOT 2.5m natural coloursatellite imagery through a low cost methodology. The software utilized wereArcGIS Desktop 10.1 suite, ENVI 4.5, Google Earth and Global Mapper 15. The methodology includedscanning, geo-referencingwith Root Mean Square error (RMS) of $0.000590169 \mathrm{~m}$, which was tolerable within the research specification (RMS $\leq$ $0.009 \mathrm{~m})$, image data validation, image visualization and interpretation, on-screen vectorisation and feature extraction,satellite image enhancement, image classification,contour interpolation from digital elevation model (DEM), field verification and completion, editing, cartographic embellishment, quality control and printing of the updated map.The updated topo map when overlaid on the old topo sheetdepicted that most parts of the study area had experienced tremendous development. For instance, the built-up area had a total increase of 9,630.389Ha which is as a result of massive urban migration that has taken place over the years a common trend observed in most Nigerian cities. However, the farm land and forest land decreased by 3,116.400Ha and 6,410.934Ha respectively which could be attributed to the massive development that has taken place in the study area over the years. Another significant change was in the length of roads which was $716.565 \mathrm{~km}$ in 1967 but increased to approximately $1,229.674 \mathrm{~km}$ in 2015 . The interpretation of the satellite image and field verification solved doubts in the updating process and had an important contribution to the updated map. The results of the analysis showed that the use of digital mapping techniques for updating topo maps is fast and cost effective.
\end{abstract}

Keywords: Topographic map, SPOT image, Map updating, Digital mapping techniques, DEM

\section{Introduction}

From the earliest civilization, maps have been used to portray information about the earth's surface. Navigators, land surveyors, town planners, the military and architects used maps to show spatial distribution of important geographic features. Once produced, this graphic image (Map) becomes static, therefore, it should be expected that a map may be partly out-of-date by the time of its publication and it may have to continue in this state for a period of time (Keates, 1973). Nigeria's topographical maps and by extension The Topographic Map of Okigwe were produced in the past from aerial photographs using complex processes based on Photogrammetry. Some of the maps in Nigeria are old, outdated and largely exist in analogue form. Due to the high cost of aerial photography, these maps have not been updated for many years and as such does not have enough information useful for planning, decision-making and navigation purposes. Therefore, there is an urgent need to produce new maps or update existing old maps of Nigeria. Cost-effective updating of maps using digital mapping techniques are being employed these days. The capabilities and potential of satellite remote sensing in modern day mapping, the flexibility and dynamism of digital mapping techniquesprovides value-added products for quality planning and decision-making.Considering the methods used in compiling and drawing of the old maps, there is need for an update of our topographical maps using high resolution imageries which are more accurate. The Earth surface is changing rapidly by the waves of human and natural activities, the course of a river channel may change fairly rapidly as a result of flooding, Landslides may also alter the topography significantly, roads may be added or some go out of use. Because of these changes, it is important to have a fairly recent (or recently updated) topographic map to ensure accuracy when they are put into use.The recent availability of high resolution satellite imagery has increased the interest in the use of satellite data for topographic mapping applications. The SPOT $2.5 \mathrm{~m}$ natural colour imagery and $10 \mathrm{~m}$ Digital Elevation Model (DEM) provides a good starting platform by which such endeavours may be attained.

\subsection{Aim and objectives}

The main aim of this paper is to show the effectiveness of digital mapping techniques in updating the topographic map of Okigwe L.G.A at 1:50,000scale using orthorectified SPOT $2.5 \mathrm{~m}$ natural colour satellite imagery through a low cost methodology. The Objectives of the study are as follows: 


\section{International Journal of Science and Research (IJSR) \\ ISSN (Online): 2319-7064}

Index Copernicus Value (2013): 6.14 | Impact Factor (2014): 5.611

- To convert the existing topographical sheet from analogue to digital format.

- To use digital mapping techniques to capture topographic features from the satellite imagery.

- To process and overlay the data with existing maps of the study area so as to correlate the geo-information for updating the topographic map of Okigwe at 1:50,000scale.

- To evaluate the results in terms of informative content and geometric precision of the final adopted composition toupdating.

\section{Study Area}

Okigwe Local Government is one of the 27 Local Government Areas (LGA's) in Imo State. It is located between latitudes $5^{0} 56^{\prime} 24^{\prime \prime} \mathrm{N}$ to $5^{0} 42^{\prime} 19^{\prime \prime} \mathrm{N}$ and longitudes $7^{0} 12^{\prime} 58^{\prime \prime} \mathrm{E}$ to $7^{0} 24^{\prime} 02^{\prime \prime} \mathrm{E}$. It is boundedto the North by Orumba South LGA of Anambra State and UmuNneochiLGA of Abia State, to the East byIsuikwatoLGA of Abia State and to the South by Umuahia North LGA of Abia State, Ihitte/Uboma and Ehime MbanoLGA's both of Imo State while Onuimo and Ideato-NorthL.G.A's both of Imo State forms the border to the west. The Imo River forms the natural boundaries between Okigwe LGA and a few of these neighbouring Local Government areas such as Onuimo and Ehime MbanoLGA's (see Fig. 1).Okigwe L.G.A is found in the tropical rainforest region of Nigeria. It is according to (NEST 1991) the natural rainforest (Riparian forest and Low land forest). It is drained mainly by River Imo and it tributary streams. Like most towns in Nigeria, it experiences two distinct climatic seasons; namely dry (October to March) and wet (April to September) seasons. A period of cold, dry, dusty winds known as "Harmattan" occurs from December to February annually. Okigwe L.G.A has a mean temperature range between $24^{\circ} \mathrm{C}$ to $34^{\circ} \mathrm{C}$ with a relative humidity of $70 \%$ in dry months and $90 \%$ in wet months. The hottest months are between January and March (NIMET 2009). Okigwe L.G.Ais the fourth largest LGA in Imo state of Nigeriain terms of land mass with a projected 2014 population of about 169,861 people (National Population Commission NPC, 2006) unevenly distributed over a total land area of $32,037.445$ hectares. Most of the population is made up of immigrant workers from other states. Okigwe L.G.A shares partly with IsuikwatoL.G.A of Abia State the primary host site of the old Imo State University (now Abia State University). Okigwe has various tourist and historical sites.Okigwe also has a number of secondary schools namely;Federal Government CollegeOkigwe, Agbobu community secondary school, Community secondary school Okigwe, Girls secondary schoollhube, Ihubeboys high school, Urban secondary school Ubahaamong others.

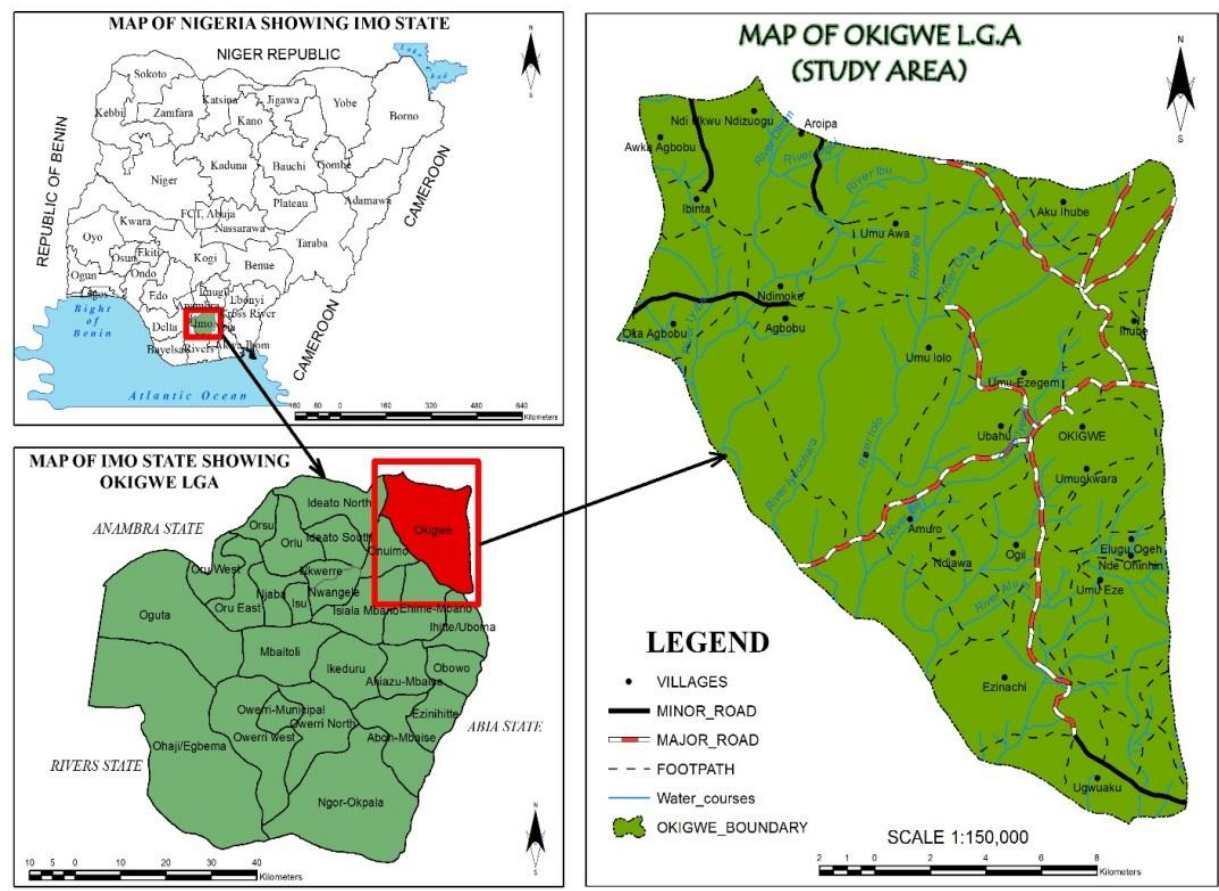

Figure 1: Map showing study area

Source: Map digitized from the administrative map of Nigeria 2012 obtained from OSGOF

\section{Methodology}

\subsection{Data Acquisition}

The main materials used in this study were obtained from both primary and secondary sources. The Old topo map of Okigwe at scale 1:100,000 (1967) was acquired from the Ministry of Lands and Survey Owerri, Imo State while theorthorectified SPOT5 $2.5 \mathrm{~m}$ natural colour satellite imagery of Okigwe L.G.A and the $10 \mathrm{~m}$ DEM covering the study area were acquired from the Office of the Surveyor General of the Federation of Nigeria (OSGOF).
Table 3.1 shows the data acquired and source

\section{Volume 4 Issue 11, November 2015}




\section{International Journal of Science and Research (IJSR) \\ ISSN (Online): 2319-7064}

Index Copernicus Value (2013): 6.14 | Impact Factor (2014): 5.611

Table 3.1: Data type and source

\begin{tabular}{|c|c|c|c|c|}
\hline $\mathbf{S} / \mathbf{N}$ & Data Type & $\begin{array}{c}\text { Production } \\
\text { Date }\end{array}$ & SCALE & SOURCE \\
\hline 1 & $\begin{array}{l}\text { SPOT } 5 \\
\text { Satellite } \\
\text { Imagery }\end{array}$ & 2012 & $2.5 \mathrm{~m}$ resolution & OSGOF \\
\hline 2 & SPOT DEM & 2012 & $10 \mathrm{~m}$ resolution & OSGOF \\
\hline 3 & $\begin{array}{c}\text { Topographic } \\
\text { map of Okigwe }\end{array}$ & 1967 & $1: 100,000$ & $\begin{array}{l}\text { Ministry of } \\
\text { Lands and } \\
\text { Survey } \\
\text { Owerri, } \\
\text { Imo State }\end{array}$ \\
\hline 4 & $\begin{array}{l}\text { Admin Map of } \\
\text { Nigeria }\end{array}$ & 2012 & $1: 2,000,000$ & OSGOF \\
\hline 7 & $\begin{array}{l}\text { Gazetteer of } \\
\text { place names }\end{array}$ & 2012 & NIL & OSGOF \\
\hline 8 & $\begin{array}{c}\text { Quickbird } \\
\text { Satellite image }\end{array}$ & 2012 & $1 \mathrm{~m}$ resolution & OSGOF \\
\hline
\end{tabular}

\subsection{Data Processing}

\subsubsection{Image Data Validation}

The level of geo-rectification applied to a satellite imagery varies depending on the type. However, it is in best practice to verify or validate any imagery acquired either by an existing map(s) within or outside the area to be mapped, if the map is of sufficient accuracy, or an imagery with higher accuracy, or by using ground control points obtained by geodetic measurements, depending on the accuracy required for the particular project.

For this study, the acquired Ortho-rectified SPOT $5(2.5 \mathrm{~m}$ resolution, ortho level 3), accompanied with DEM $10 \mathrm{~m}$, were subjected to the following validation tests before being used:

- The information contents of the SPOT 5 imagery were evaluated by visual interpretation of the image in terms of the manual feature detection, recognition, tracing, and pointing potential using the georeferenced old Okigwe topo map, since both the image and the topo map are in the same coordinate system.

- The georeferencedTopo map was also overlaid over the satellite imagery cross check whether the features on the imagery matches the Topo map.

- Four GPS ground control points were obtained from the Office of the Surveyor General, and their values (in WGS 84) were plotted on the imagery, and they all located about $3 \mathrm{~m}$ away from their true positions.

- Besides, navigation coordinates were captured, using Garminetrex20 hand held GPS receiver, in the field at road junctions to verify the accuracy of the ortho-rectified SPOT 5 imagery; and

- Finally, available Quick Bird imagery of $0.6 \mathrm{~m}$ resolution (in WGS 84 datum) covering part of the project area was obtained from OSGOF, and it was overlaid on the SPOT 5 imagery to cross check whether the imageries matched each other, however, a small insignificant shift was noticed.

The results from the above validation tests revealed that the level of ortho-rectification of SPOT 5 satellite imagery was good enough for the mapping at 1:50,000scale. The positional accuracy of SPOT 5 imagery is superior at plus or minus five meters $( \pm 5 \mathrm{~m})$, and the accuracy of the handheld
GPS used stands at plus or minus 3 meters $( \pm 3 \mathrm{~m})$. This is why SPOT 5 imagery was used for this study without further geometric rectification by geodetic means.

\subsubsection{Satellite Image Enhancement}

The SPOT $2.5 \mathrm{~m}$ imagery is a natural colour composite. The colours of natural features such as water bodies and vegetation appear as they are on ground and the image is fairly close to reality. However, due to insufficient contrast between and among many objects on the imagery, the vegetation types are not easily distinguished and some shallow water areas seem to have similar reflectance with the wetlands. The imagery is composed of 3 bands. The enhancement operation performed basically consisted of splitting the multispectral SPOT image composite into individual Red Green Blue (RGB) channels and then recompositing these bands by changing their grouping. Selecting the appropriate band combination to use in the composite does have a huge impact on increasing the contrast between features to aid easy detection and classification by our remote sensing system.

\subsubsection{0n-screen Vectorization and Feature Extraction}

Several features are easily distinguishable to a good degree on the image. These include roads, water bodies, streams, sand dunes and built up areas thus, shapefiles were created for each feature in the Arc Catalog environment. These features were then extracted by on-screen vectorization using the appropriate shapefile. Point mode digitizing strategy was adopted in this case. Some points were selected subjectively because some judgement is required on how to represent some lines. The default editing mode in ArcGIS is point mode. In this mode, a series of precise points, or vertices were digitized. ArcMap then connects the vertices to create the digital features.

\subsubsection{Image Classification (Unsupervised method)}

Preliminary image interpretation revealed such a multitude of features visible on the satellite image that it was deemed impractical to subject all of them to on-screen vectorization. More so, the low contrast between some adjoining features even after enhancement would greatly task the human digitizer in trying to delineate their exact boundaries. As such, it was necessary to employ image classification. Image classification helps to process the image by categorizing the land into various land use functions. The supervised and unsupervised methods were each put up for consideration.

The large quantity of features to be handled made it more practical to use unsupervised classification. There are several different unsupervised classification algorithms that are commonly used. The two most frequently used algorithms are the K-means and the ISODATA clustering algorithm. ENVI remote sensing software was used in this regard to implement the K-Means algorithm for the images.

K-Means unsupervised classification calculates initial class means evenly distributed in the data space then iteratively clusters the pixels into the nearest class using a minimum distance technique. Each iteration recalculates class means and reclassifies pixels with respect to the new means. All pixels are classified to the nearest class unless a standard deviation or distance threshold is specified, in which case

\section{Volume 4 Issue 11, November 2015}




\section{International Journal of Science and Research (IJSR) \\ ISSN (Online): 2319-7064}

Index Copernicus Value (2013): 6.14 | Impact Factor (2014): 5.611

some pixels may be unclassified if they do not meet the selected criteria. This process continues until the number of pixels in each class changes by less than the selected pixel change threshold or the maximum number of iterations is reached.

To reduce processing time, spatial sub setting was done to limit the application of the K-Means function to the areas of concentration on the image. After the classification, decisions were then made concerning which land cover category fell within.

\subsubsection{Contour interpolation from DEM}

The SPOT $10 \mathrm{~m}$ digital elevation model (DEM) is basically a surface model with a rectangular grid of pixels with the digital numbers corresponding to height values. Several terrain parameters can be extracted from such a surface for the depiction of relief on the topographic map. For the purposes of the 1:50000 mapping, contours at 10m interval and spot elevations of mountainous peaks and low valley floors were extracted from the DEM using Global Mapper software.

One major requirement for deploying contours interpolated from DEMs for use in mapping is that the contours must be of good cartographic quality hence, a smoothing function was applied to the contour lines to improve their aesthetic quality. The Polynomial Approximation with Exponential Kernel (PAEK) function was used. PAEK calculates smoothed lines using a parametric continuous averaging technique

A suitable tolerance was selected and applied for use in the operation. The smoothing tolerance specified the length of a "moving" path along an input line used to calculate the smoothed coordinates by PAEK algorithm. The longer the path, the more smoothed the resulting lines. Each new location was calculated using the information within the specified length of the path that was centered at the location.

\subsubsection{Field Verification and Completion}

The $2.5 \mathrm{~m}$ SPOT 5 natural colour satellite imagery used in this study contains a wealth of information that can be recognised and positively identified with experience and ground truthing. However, some details like foot paths and small settlements may not be positively identified and classified but their presence can sometimes be inferred from the associated surrounding details. Therefore, in order to ensure a high fidelity of detail content of the map, extensive field verification and completion exercise were carried out to achieve the following objectives:

- To obtain/verify the names of all settlements on the map;

- To classify the road networks (into footpaths, major, minor etc.);

- To verify the vegetation classes ;

- To obtain/verify the names of rivers ;

- To obtain/verify names of hills, mountains and other cultural details;

- To obtain the coordinates and names of all facilities transformers, power line, court, school, hospital, police station, church, mosque, telecom/wireless masts, post office, airport, prison, fire station, cemetery, hotel, petrol station, antiquity, market, museum, government

buildings, public facilities, military bases etc.

- To obtain the coordinates and names of all forest reserves and plantations ;

- Trace /sketch all features not shown on map

The points (coordinates) acquired during the ground truthing exercise were entered into Microsoft Excel Worksheet and later imported into the ArcMap environment, converted to shapefile and added as a layer on the map for proper correction, identification of features on the map and also for feature annotation and place names.

\subsubsection{Integration of Ground-truth data and Quality Control}

Data obtained from the ground truthing exercise were incorporated to refine both the preliminary classification system and the preliminary image interpretation. In some cases, this stage involved re-labelling and redrawing of certain feature boundaries to give the actual representation as revealed by the field verification exercise. Quality control involved cross-checking the feature boundaries to ensure accurate and consistent interpretation. Updates and corrections noticed or observed in the field were effected during this stage. Besides, errors arising from the digitizing such as overshooting, undershooting, overlaps, intersections, edge matching,etc. were all checked for. To check accuracy of streams digitized from the satellite image, sub-watersheds were delineated from the DEM for the extraction of stream networks based on flow direction and accumulation. The watersheds were delineated from the DEM by computing the flow direction and using it in the Watershed function. The Watershed function uses a raster of flow direction to determine contributing area. These stream networks were then used to adjust those digitized from the image where necessary.

\subsubsection{Cartographic Enhancement and Production of Updated map}

Classic symbolization techniques in ArcGIS were applied to the feature classes for good cartography.Intuitive, easy to use editing tools provide high-quality map finishing. In cases where the default symbols within ArcGIS did not suffice, custom map elements were produced using CorelDraw software as enhanced metafiles (*emf) and then imported into the ArcGIS environment to aid in representations of the topography. A uniform graticule gridding set in both a geographic and projected coordinate system referenced to Minna datum was used. With careful representations of the symbology and geometry of features through rules and interactive editing tools, the visualization of feature classes and manipulated graphic elements that enhance the communication of the map was refined.

In addition to the standard drawing and layout tools, more graphics and effects tools were incorporated to help with detailed finishing tasks within the mapping environment.

It should be accentuated however, that although ArcMap was used, the methodology is not dependent on the software for the case study. 


\section{International Journal of Science and Research (IJSR) \\ ISSN (Online): 2319-7064}

Index Copernicus Value (2013): 6.14 | Impact Factor (2014): 5.611

\section{Result and Analysis}

The results of this research is an updated topographic map of Okigwe, with additional information about map accuracy and tables concerning information content.

\subsection{Updated Topographic Map}

Figure 4 shows theupdated map at 1:50,000 scale produced from the SPOT $2.5 \mathrm{~m}$ satellite image and $10 \mathrm{~m}$ DEMof Okigwe L.G.A.

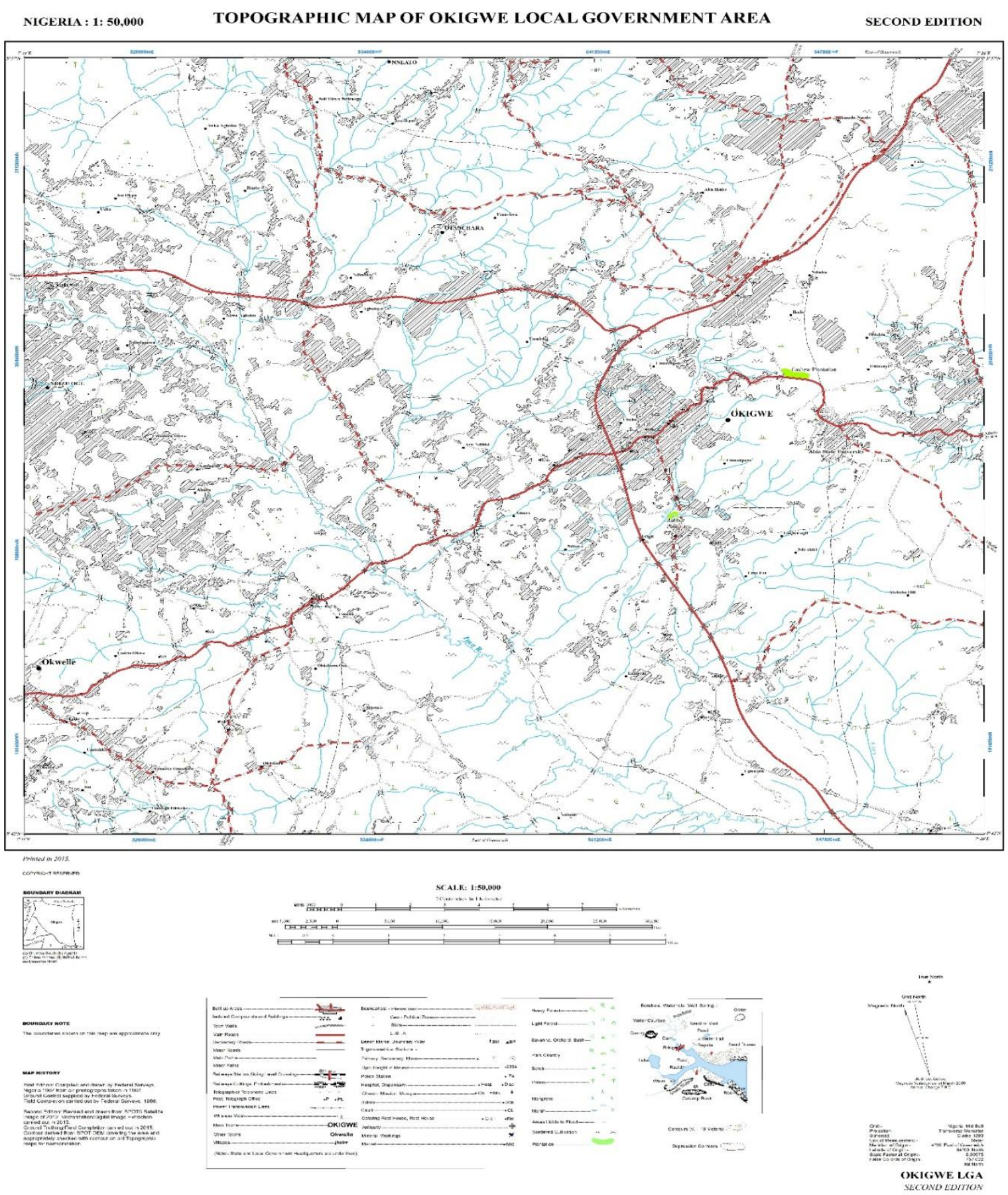




\section{International Journal of Science and Research (IJSR) \\ ISSN (Online): 2319-7064}

Index Copernicus Value (2013): 6.14 | Impact Factor (2014): 5.611

\begin{tabular}{|c|c|}
\hline For Distance Pl-P2 & For Distance P3-P4 \\
\hline$\nabla N=618$ & $\nabla N=-121$ \\
\hline$\nabla \mathrm{E}=1256$ & $\nabla \mathrm{E}=276$ \\
\hline $\mathrm{L}=\sqrt{ } \nabla \mathrm{E}^{2}+\nabla \mathrm{N}^{2}$ & $\mathrm{~L}=\sqrt{\nabla} \mathrm{E}^{2}+\nabla \mathrm{N}^{2}$ \\
\hline $\mathrm{L}=\sqrt{(1256)^{2}+(618)^{2}}$ & $\mathrm{~L}=\sqrt{(276)^{2}+(-121)^{2}}$ \\
\hline$L=\sqrt{ } 1,959,460$ & $\mathrm{~L}=\sqrt{90,817}$ \\
\hline $\mathrm{L}=1,399.807 \mathrm{~m}$ & $\mathrm{~L}=301.359 \mathrm{~m}$ \\
\hline Map distance $=1,399.767 \mathrm{~m}$ & Map distance $=301.782 \mathrm{~m}$ \\
\hline Difference $=0.04$ & Difference $=0.423$ \\
\hline $0.04 / 1,399.807$ & $0.423 / 301.359$ \\
\hline$=2.8575 \times 10^{-5}$ & $=0.001404$ \\
\hline Reciprocal $\left(2.8575 \times 10^{-5}\right)$ & Reciprocal (0.001404) \\
\hline $1 / 34,995.175 \mathrm{~m}$ & $1 / 712.433 \mathrm{~m}$ \\
\hline
\end{tabular}

Figure 4: The updated topographic map of Okigwe L.G.A (without the elevation features)

\subsection{Map Accuracy}

In other to check the accuracy of the map GPS coordinates of four road junctions identified on the map was obtained on ground; these coordinates were then used to compute their straight line distances and then compared with the distances measured on the map which was later used to calculate their reciprocal.

Table 4.1: Coordinates of road junctions obtained using Garmin etrex 20 hand held GPS receiver

\begin{tabular}{|c|c|c|}
\hline STN_ID & $\begin{array}{c}\text { EASTHING } \\
(\mathbf{m E})\end{array}$ & $\begin{array}{c}\text { NORTHING } \\
(\mathbf{m N})\end{array}$ \\
\hline P1 & $541754 \mathrm{mE}$ & $201398 \mathrm{mN}$ \\
\hline P2 & $543010 \mathrm{mE}$ & $202016 \mathrm{mN}$ \\
\hline P3 & $547973 \mathrm{mE}$ & $202418 \mathrm{mN}$ \\
\hline P4 & $548249 \mathrm{mE}$ & $202297 \mathrm{mN}$ \\
\hline
\end{tabular}

The results shows that the map has a high accuracy.

\subsection{Information Content}

The measurement of the information content was made usingthe measure tool on ArcMap, the length was calculated in kilometers $(\mathrm{Km})$ andareas in hectares (Ha). The quantitative evaluation of old and updated features is presented in Table 4.2

Table 4.2: Length and area of features from old topo map and updated topo map.

\begin{tabular}{|l|l|l|l|l|}
\hline Features & \multicolumn{2}{|c|}{ Old Topographic Map } & \multicolumn{2}{|c|}{ Updated Topographic Map } \\
Studied & Length $(\mathrm{Km})$ & Area $(\mathrm{Ha})$ & Length $(\mathrm{Km})$ & Area $(\mathrm{Ha})$ \\
\hline Roads & 716.565 & & $1,229.674$ & \\
\hline Farm land & $9,984.133$ & & $6,867.733$ & \\
\hline Forest land & $17,989.422$ & & $11,578.488$ & \\
\hline Watercourses & 461.255 & & 724.700 & \\
\hline Built up area & 701.735 & & $10,332.124$ & \\
\hline Waterbody & 48.803 & & 195.210 & \\
\hline TOTAL & $\mathbf{1 , 1 7 7 . 8 2 0}$ & $\mathbf{2 8 , 7 2 4 . 0 9 3}$ & $\mathbf{1 , 9 5 4 . 3 7 4}$ & $\mathbf{2 8 , 9 7 3 . 5 5 5}$ \\
\hline
\end{tabular}

During the field verification exercise it was discovered that most of the features identified and extracted from the satellite image was accurate and consequently solved doubts in the updating process. Table 4.2 shows that the resulting map added a large quantity of information to the old map. The increase of roads in the updated map is due to the massive development that has taken place in the past 48 years. The watercourses and waterbodiesincreased by approximately $263.475 \mathrm{~km}$ and $146.407 \mathrm{Ha}$ respectively.Also, the farmland and forest land reduced by $3,116.4 \mathrm{Ha}$ and $6,410.934 \mathrm{Ha}$ respectively. Finally, the built-up area had a total increase of $9,630.389 \mathrm{Ha}$ as a result of massive urban migration that has taken place over the years a common trend observed in most Nigerian cities.

\section{Conclusion}

Given the diversity and heterogeneity of the natural and human altered landscape, it is obvious that the timehonoured and laborious method of ground inventory by classical surveying is cumbersome for topographic mapping over large areas. A more synoptic vantage point, as provided by remote sensing is required for effective detection, identification, classification, delineation, and analysis of landscape features. The project took two months to execute while the analogue method provided by classical surveying would have taken more than six months to actualize, this also applies to the cost implication in terms of logistics. The result of the updated topographic map of Okigwe therefore shows the cost-effectiveness of digital mapping techniques in updating topographic maps at the 1:50,000 scale. The interpretation of the satellite image and field verificationexercise solved doubts in the updating process and had an important contribution to the updated map.

\section{References}

[1] Adesina, J.G. (2005). Revision of Nigeria 1:2500 Township Map Using Cadastral Techniques in OwoGRA, Ondo State. Ph.D. Project Proposal, Department of Geography and Regional planning, Ambrose Ali University, Ekpoma, Nigeria.

[2] Atilola, O., (1989). "Revision and Production of 1:50,000 Maps Using SPOT Satellite Imagery" Paper Presented at the 25th Annual Conference of the Nigerian Institution of Surveyors, Kano, Kano State. 


\section{International Journal of Science and Research (IJSR) \\ ISSN (Online): 2319-7064}

Index Copernicus Value (2013): 6.14 | Impact Factor (2014): 5.611

[3] Ayeni, O. O., (2009). Lagos State Digital Mapping and GIS Project: An overview paper presented at the second stakeholder forum held at Lagos, Nigeria.

[4] Balogun, O. Y., (1987). The Directorate of Overseas Surveys and Mapping in Nigeria. The Cartographic Journal, Vol.24, No.1, PP 3-14.

[5] Brandenberger, A.J. and Ghosh, S.K. (1985). "The World' Topographic and Cadastral Mapping Operation" Photogrammetric Engineering and Remote Sensing, Vol L1:437-444.

[6] Fajemirokun, F.A. and Nwilo, P.C. (1996). An Overview of the surveying and mapping activities in Nigeria and future prospects. A paper presented at the 1996 NIS AGM Oyo state.

[7] Keates, J.S., (1973). Cartographic Design and Production, Longman University of Michigan New York: Longman Publishers.

[8] Keates, J.S., (1982). Understanding Maps. New York: John Wiley \& Sons Inc. 139p.

[9] Meneguette, A.A.C., (1987). Cartographic accuracy and information content of space imagery for digital mapcompilation and map revision. London, Ph.D. Thesis - University College of London. 464p.

[10] Olaore, L.Y., (2004). An integrated use of SPOT X5 and GPS data for updating topographic maps in a GIS environment. M.Sc. Thesis of the Federal University of Technology, Minna.

[11] Sadeghi,N.F., (2004). Evaluation of potential of SPOT 5 $\mathrm{HRG}$, high resolution satellite imageries for 1: 25000 scale maps revision, Proc. XXthISPRS Congress 2004, Istanbul, Turkey, pp.478-483.

\section{Author Profile}

Dr. Augustine C. Emeribeole is serving at Imo State University, Department of Surveying and Geoinformatics, Owerri, Nigeria. Email: acemeribephd@gmail.com

Chima J. Iheaturu is serving at Imo State University, Department of Surveying and Geoinformatics, Owerri, Nigeria. Email: chima.geomaven@gmail.com 